\title{
Comparative molecular dynamics study of fcc-Ni nanoplate stress corrosion in water
}

Osvalds Verners ${ }^{\mathrm{a}}$ and Adri C.T. van Duin ${ }^{\mathrm{a}^{*}}$

${ }^{\mathrm{a}}$ Department of Mechanical and Nuclear Engineering, Pennsylvania State University, 136 Research East

Building, University Park PA 16802, USA, e-mail: acv13@psu.edu, phone: +1-814-863-6277

*Corresponding author

\section{Abstract}

Reactive molecular dynamics studies of stress corrosion properties of Ni metal nanoplate structures in pressurized water at different temperatures, chemical environments and mechanical boundary conditions have been performed. The results indicate reduction of dislocation nucleation barriers due to the water reactions on material surfaces, simulated loading rate and elevated temperature, resulting in reduction of material strength and ductility. It is also found that pre-oxidized surfaces yield increased initial dislocation nucleation barriers. Likewise, significant effects of stress triaxiality on strength, ductility and surface reactivity are also observed by comparison of boundary conditions. Size dependent structure failure modes and distributions of stress and strain have been explored. A possible Ni dissolution mechanism is identified and validated using DFT calculations and metadynamics simulations.

Keywords: Ni, stress corrosion cracking, molecular dynamics, ReaxFF

\section{Introduction}

Among the environmentally assisted cracking (EAC) structural material failures a few main types can be distinguished [1]. These include stress corrosion cracking (SCC), which occurs through a material's interaction in stressed state with chemically active fluid environment species, and hydrogen caused embrittlement (HE) due to bulk dissolved atomic hydrogen, which tends to migrate to high stress regions. Both phenomena have been explored extensively both experimentally and computationally for a wide range of materials. A comprehensive review of known and suggested SCC and HE mechanisms, as well as outstanding issues, can be found in [2]. A review of $\mathrm{H}$ diffusion and dislocation channeling related intergranular SCC and irradiation assisted SCC studies is published in [3]. In particular, detailed atomistic 
failure mechanisms involving increased dislocation emission barriers by $\mathrm{H}$ atoms on crack surface [4, 5], reduced dislocation emission barriers by $\mathrm{H}$ atoms on the slip plane [5], $\mathrm{H}$ migration to crack tip [5, 6], as well as combined atomistic/kinetic models $[6,7]$ have been presented. Moreover, the dislocation nucleation inhibition by a single $O$ impurity atom at a crack tip of a single metal in static calculations [4] and stress enhanced metal segregation and $\mathrm{H} / \mathrm{O}$ inward diffusion in alloy type structures at elevated temperature [8] have been suggested as possible early stage EAC mechanisms. A more general discussion of solid materials brittleness and crack healing probability, based on a comparison of the electronic bonding structure from DFT calculations on $\mathrm{Al}$ and $\mathrm{Al}_{2} \mathrm{O}_{3}$, can be found in [9]. Moreover, analytical models, based on the combination of crack tip mechanics and oxidation kinetics in alloys, have been developed [10-12]. The models refer to consecutive stage mechanisms of open surface dissolution, oxidized film formation and thickening, solid state oxidation during steady state passivation and strain facilitated rupture, which produces new open surfaces. The significance of alloy composition has been studied experimentally, e.g., for a Ni-Cr alloy [13], which indicates simultaneous processes of alloy component diffusion and oxygen penetration ahead of crack tips and along grain boundaries, or for a $\mathrm{Ni}$ base superalloy [14], which indicates that dense grain boundary precipitates may reduce intergranular stress corrosion cracking (IGSCC) due to crack blunting effects. Furthermore, the room temperature reactivity properties as functions of electric field [15] or electrochemical potential [16] have been explored. However, to the best of our knowledge, there are no atomistic level dynamic simulation results published on $\mathrm{Ni}$ or $\mathrm{Ni}$ base alloy behavior in reactive water environment under mechanical strain conditions. Since we consider it important for understanding and improving similar type material stress corrosion properties for structural applications in corrosive environment, this study is devoted to the modeling of corrosion assisted failure behavior of Ni structures in pressurized water. The reactive molecular dynamics simulation study is focused on a comparison of notched Ni nanoplate deformation behavior under fixed lateral stress or strain conditions and, subsequently, on comparison of pristine vacuum, pre-oxidized vacuum and oxidizing pressurized environments. Finally, a water-assisted Ni dissolution mechanism is proposed.

\section{Material and Methods}

For the current EAC study water was chosen as a generalized EAC environment for single-crystal fcc-Ni as an example of a refractory alloy component with known water reaction mechanisms [15-18], with the aim of estimating the corrosive effect on single-metal structure components with defects under plastic deformation. 
A $\{111\}$ plate with periodic dimensions of $29.8 \times 8.6 \AA(110 /[112])$, thickness of $30.4 \AA$ and an elliptical 3 layers wide 111(112) notch was simulated. $256 \mathrm{H}_{2} \mathrm{O}$ molecules at an initial density of $1.0 \mathrm{~g} / \mathrm{cm}^{3}$ were added for the corrosive environment simulation.

The simulations were performed with the LAMMPS $[19,20]$ implementation of the ReaxFF reactive force field, as described in [21]. The [15] Ni/O/H system force field version was used. As Table 1 indicates, approximate agreement has been obtained for the elastic constants and USF energy, whereas fracture and full dislocation occurrence probability may be reduced due to the high $\mathrm{K}_{\mathrm{Ic}}$ and low ISF energy values, respectively. Subsequently, an absolute stress value analysis was not considered for this study, instead focusing on relations between reactivity and stress states.

Table 1. fcc-Ni elastic constants, fracture toughness values, intrinsic and unstable stacking fault energies.

\begin{tabular}{|l|l|l|l|l|l|l|l|}
\hline & $\mathrm{C}_{11}(\mathrm{GPa})$ & $\mathrm{C}_{12}(\mathrm{GPa})$ & $\mathrm{C}_{44}(\mathrm{GPa})$ & $\begin{array}{l}\gamma(\mathrm{kJ} / \mathrm{mol} \\
\text { per atom) } \\
\{100\}\end{array}$ & $\begin{array}{l}\gamma(\mathrm{kJ} / \mathrm{mol} \\
\text { per atom) } \\
\{111\}\end{array}$ & $\mathrm{ISF}^{\mathrm{a}}\left(\mathrm{mJ} / \mathrm{m}^{2}\right)$ & $\mathrm{USF} \mathrm{F}^{\mathrm{a}}\left(\mathrm{mJ} / \mathrm{m}^{2}\right)$ \\
\hline reference & $246.5[22]^{\mathrm{b}}$ & $147.3[22]^{\mathrm{b}}$ & $124.7[22]^{\mathrm{b}}$ & $77.8[23]^{\mathrm{c}}$ & $63.6[23]^{\mathrm{c}}$ & $145[24]^{\mathrm{d}}$ & $269[24]^{\mathrm{d}}$ \\
\hline ReaxFF [15] & 217.6 & 151.2 & 151.2 & $85.4[23]$ & $61.5[23]$ & -17 & 236 \\
\hline
\end{tabular}

${ }^{a}$ ISF/USF correspond to displacement of 1 or $1 / 2$ of a $\langle 112\rangle$ (Shockley) partial dislocation, resp., the former corresponding to full $\langle 110\rangle$ dislocations by combination.

b experiment

${ }^{\mathrm{c}} \mathrm{DFT}$

${ }^{d}$ DFT (Schilfgaarde)

The simulations were performed with the constant size, pressure and temperature ensemble (NPT), using simulation step size of $0.2 \mathrm{fs}$, at $300 \mathrm{~K}$ with $100 \mathrm{fs}$ damping and $0.405 \mathrm{GPa}$ (4000 atm) with $5000 \mathrm{fs}$ damping and 2 chain thermostats on barostat. Due to the relatively small [111] dimension, the given boundary conditions are considered as plane stress conditions in [111] direction. In contrast, plane strain conditions are considered in [112] direction, which was kept fixed at its value after equilibration for all systems except for one. For the latter system a constant pressure boundary condition was applied in [112] direction for comparison. A loading regime of $5 \mathrm{e}-6 \mathrm{fs}^{-1} 0.25 \%(0.5 \mathrm{ps}) 110$ direction strain increments alternating with 5 ps relaxation periods was applied. For temperature effects estimation an additional simulation with $\mathrm{H}_{2} \mathrm{O}$ molecules at $600 \mathrm{~K}$ was performed. A cutoff radius of $10 \AA$ and simulation time increments of $20 \mathrm{ps}$ were used for the atomic strain calculation [25]. We would like add that, due to the elevated simulated pressure level (e.g., compared to primary conditions of pressurized water reactors [26]), primarily related to the density requirement $\left(\sim 1 \mathrm{~g} / \mathrm{cm}^{3}\right)$, and loading rate, limited by the computational time constraints, caution should be taken regarding predictions for the structure behavior under application conditions. 
For the $\mathrm{Ni}\left(\mathrm{H}_{2} \mathrm{O}\right)_{X}$ desorption test simulation a $\{111\}$ plate was used with periodic dimensions of $7.47 \times 8.63 \AA 110 /[112]$ ) and thickness of 5 layers, with $2^{\text {nd }}$ and $3^{\text {rd }}$ bottom layers fixed at an experimental bulk size [27]. A Ni adatom was placed at an initial fcc adsorption site. $44 \mathrm{H}_{2} \mathrm{O}$ at $1 \mathrm{~g} / \mathrm{cm}^{3}$, corresponding to $\sim 22 \AA$ plate surface separation, were used for the reactive environment representation. The [28] implementation and guidelines of collective variables and well-tempered metadynamics $[29,30]$ were applied. The single collective variable was defined as the [111] distance between the Ni adatom (fcc) and the center of mass of top surface atoms (Figure 13). A grid resolution of $0.2 \AA$, a hill weight of 0.5 $\mathrm{kcal} / \mathrm{mol}$ and a new hill frequency of $0.2 \mathrm{ps}$ were used. For the well-tempered run the bias temperature of $2700 \mathrm{~K}$, based on a non-well-tempered barrier estimate, was used.

For $\mathrm{Ni}\left(\mathrm{H}_{2} \mathrm{O}\right)_{X}$ adsorption density functional theory (DFT) energy calculations the VASP $[31,32]$ plane augmented wave (PAW) potential [33, 34] implementation was used with the generalized gradient approximation (GGA)-PBE exchange-correlation functional [35], Methfessel-Paxton smearing method [36], DFT-D3 van der Waals interaction correction method with Becke-Jonson damping [37], collinear spin polarization [38], 1e-6 eV convergence criterion for combined - Davidson block iteration [39]/residual minimization method direct inversion in the iterative subspace [40] - electronic minimization and a conjugate gradient energy convergence criterion of $1 \mathrm{e}-3 \mathrm{eV}$ for ionic relaxation. A $4 \times 9 \times 1$ k-point grid according to the Monkhorst-Pack scheme [41] and a $400 \mathrm{eV}$ plane wave basis set cutoff were used.

\section{Results and Discussion}

It was observed that during early stage of equilibration of the plate structure in vacuum the notch would heal itself by rearrangement to a single layer step. Therefore it was decided to simulate additionally plate structures in vacuum with a pre-oxidized notch in order to prevent the closure. For temperature effect and oxidation level comparison, the pre-oxidized structures were extracted from systems that had been equilibrated at $300 \mathrm{~K}, 600 \mathrm{~K}$ and $900 \mathrm{~K}$.

For the constant lateral pressure system multiple symmetric tilt grain formation events were observed. The events were identified as twinning due to partial dislocations, resulting in lattice orientation changes, including a temporary transition to the $[100] /[010] /[001]$ lattice orientation (Figure 1). The orientation changes resemble lattice orientation transformations, which can be observed for Ni wire, plate and bulk structures with free transverse deformation [42]. The latter example, which uses sample structures of close to unity aspect ratios, does not mention, however, explicit deformation mechanisms beyond partial $\langle 112\rangle$ and full $\langle 101\rangle$ dislocations in $\{111\}$ planes. Furthermore, the octahedral atomic strain distribution is 
found to be fairly uniform with respect to distance from the surfaces, which is attributed to small surface relaxation in an fcc metal as compared to a metal oxide [9] (Figure 2). Instead, the strain is concentrated in grains as they are being formed. Similarly, the octahedral stress distribution is found to be uniform across the grain bulk (Figure 3), having stress concentration in 1-2 surface layers (Figure 3a), along grain boundaries (Figure 3b,c) and in the neck forming regions (Figure 3d).

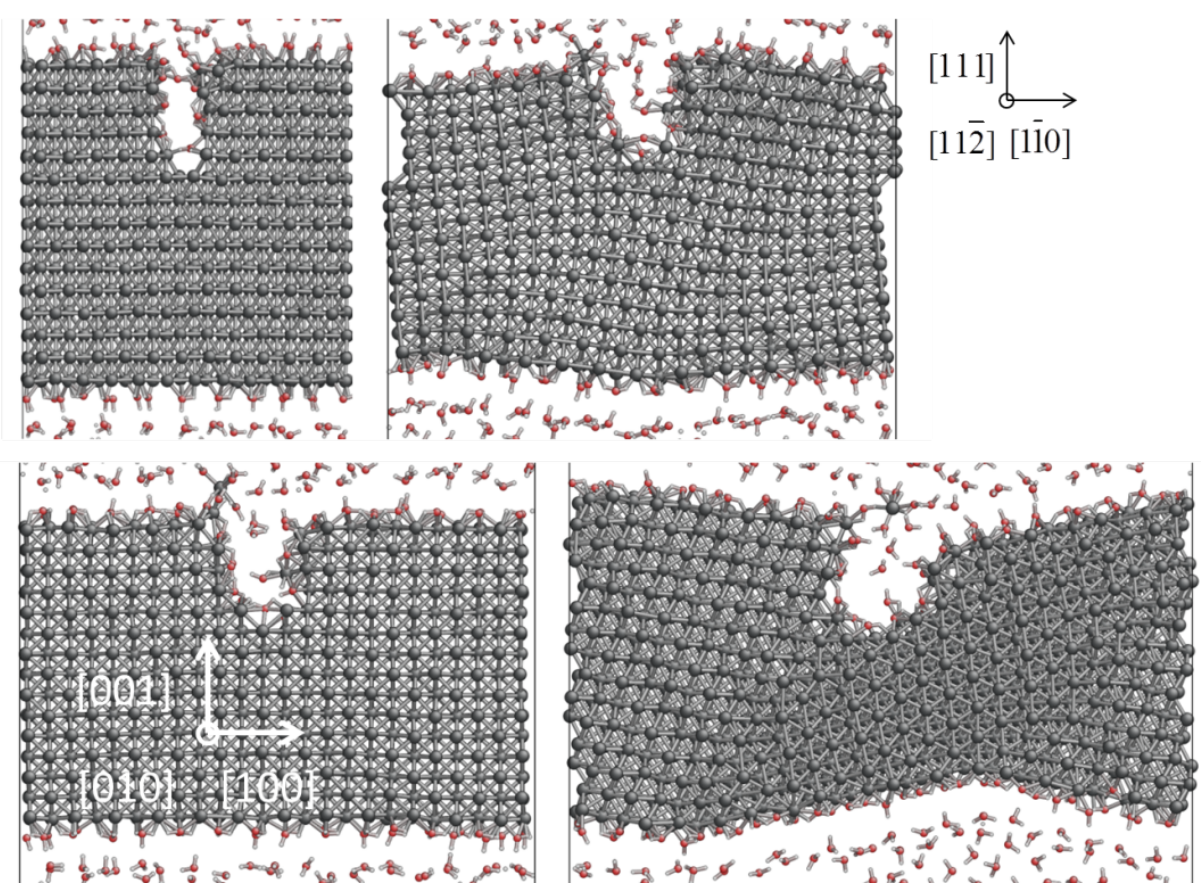

Figure 1. Configuration snapshots for a 110 strained fcc-Ni plate in water $\left(300 \mathrm{~K}, \mathrm{P}_{\text {lateral }}=\right.$ const; $\mathrm{Ni}-\mathrm{black}$, $\mathrm{O}$ - red, $\mathrm{H}$ - white).

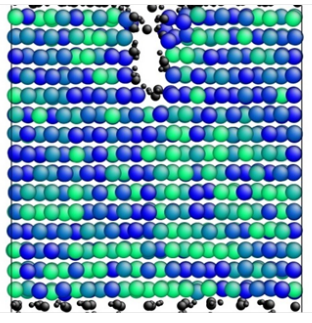

(a)

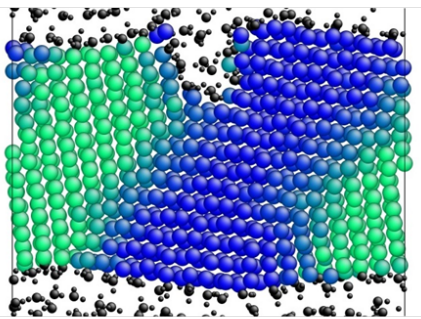

(c)

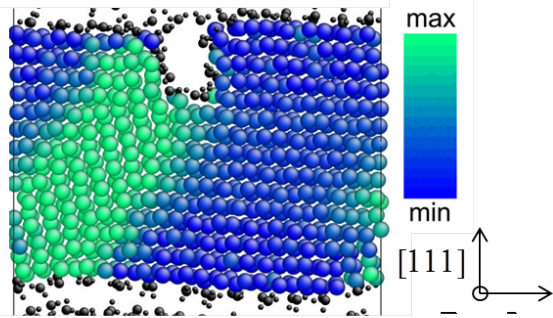

(b)
[11 $\overline{2}]$ [110]

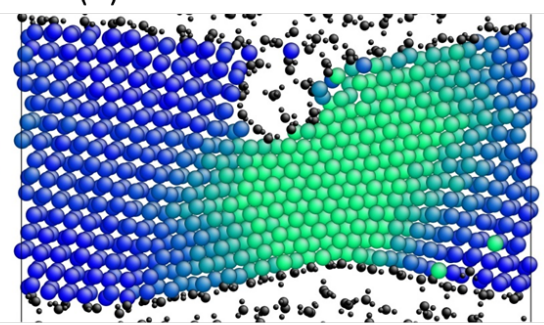

(d)

\begin{tabular}{|c|c|c|c|}
\hline configuration & $\varepsilon$ & $E_{\min }$ & $E_{\max }$ \\
\hline$a$ & 0.00 & 0.10 & 0.23 \\
\hline
\end{tabular}




\begin{tabular}{|r|r|r|r|}
\hline b & 0.27 & 0.48 & 0.64 \\
\hline $\mathrm{c}$ & 0.39 & 0.53 & 0.81 \\
\hline $\mathrm{d}$ & 0.76 & 0.43 & 0.96 \\
\hline
\end{tabular}

Figure 2. Octahedral Almansi strain distribution for a 110 strained fcc-Ni plate in water (300K, $\mathrm{P}_{\text {lateral }}=$ const $)$.

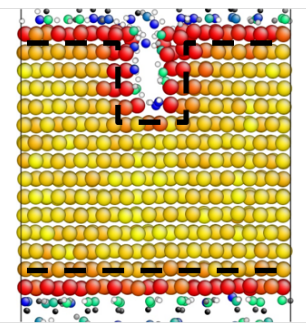

(a)

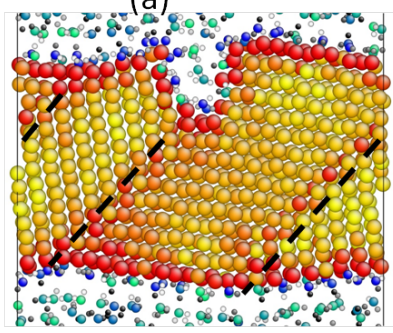

(c)

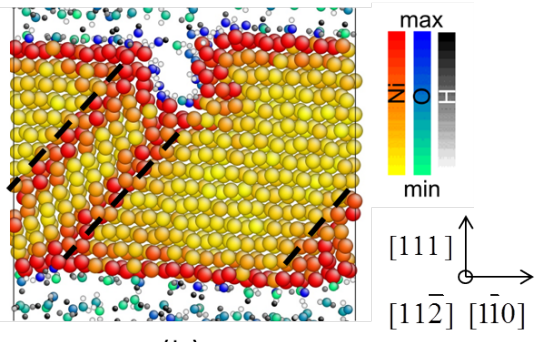

(b)

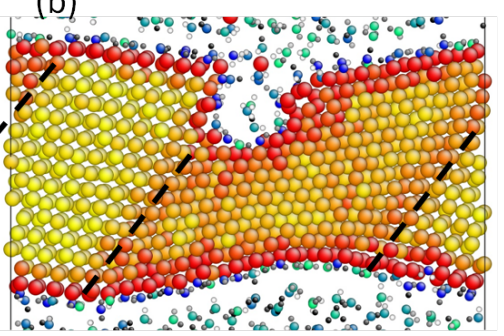

(d)

\begin{tabular}{|r|rr|r|r|}
\hline configuration & $\varepsilon$ & & $\mathrm{S}_{\min N i}(\mathrm{GPa})$ & $\mathrm{S}_{\max N i}(\mathrm{GPa})$ \\
\hline $\mathrm{a}$ & 0.00 & 10.3 & 17.3 \\
\hline $\mathrm{b}$ & 0.27 & 11.3 & 20.9 \\
\hline $\mathrm{c}$ & 0.36 & 12.8 & 22.7 \\
\hline $\mathrm{d}$ & 0.76 & 11.4 & 22.8 \\
\hline
\end{tabular}

Figure 3. Octahedral stress distribution for a 110 strained fcc-Ni plate in water $\left(300 \mathrm{~K}, \mathrm{P}_{\text {lateral }}=\right.$ const, $10 \mathrm{ps}$ time-averaged stress values with sampling frequency of $0.1 \mathrm{ps}$ ). Dashed lines indicate stress concentration regions.

In contrast, no grain formation or lattice re-orientation was observed in the fixed [112] dimension systems (discussed later in Figure 12). Subsequently, a significantly lower failure strain ( $\sim 0.6$ vs. $>0.8$ according to Figure $4 \mathrm{~b}$ and Figure 1) is predicted for the latter, which is expected due to the increased stress triaxiality. Specifically, the change in failure mechanism can be due to obstruction of slip mechanisms active in transversely free nanostructures structures and perfect bulk lattices [42] or void formation and coalescence and related creation of new dislocation nucleation locations in macroscopic structures [4345]. For the current systems the obstruction of twinning mechanism and related partial dislocations is found to be applicable, subsequently requiring new mechanisms for accommodating the applied deformation strain energy (discussed below). The observation is supported by low yielding stress and dislocation emission energy barriers for the constant lateral pressure system, as compared to the constant lateral dimension system, and presumedly similar total deformation work based strain energy capacity [1] 
estimate for both systems (Figure 4). We also observed no stable ISFs to be formed during the simulations (Figure 5) despite the initial predictions (Table 1), which we consider as a partial validation of the force field regarding the dislocation behavior of the material.

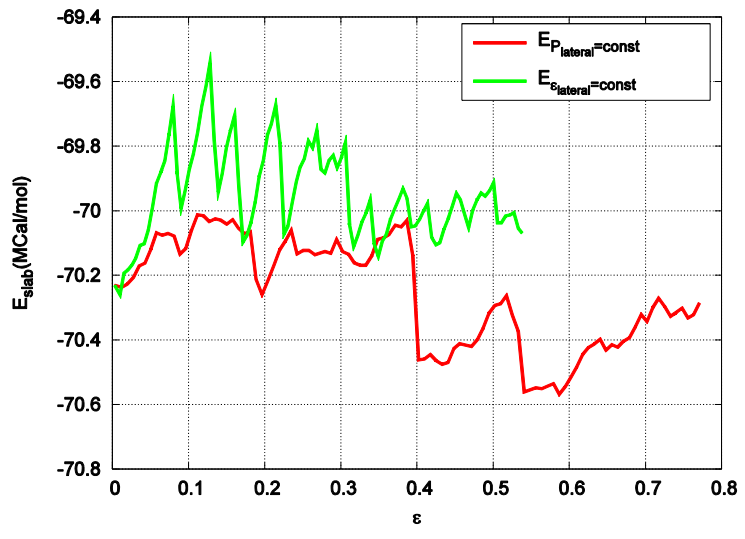

(a)

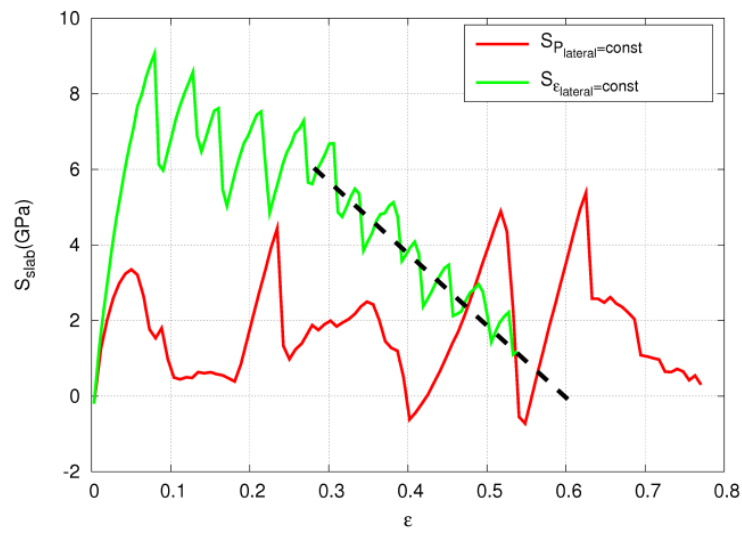

(b)

Figure 4. Potential energy (a) and tensile stress (b) vs. strain for 110 strained fcc-Ni plates in water: boundary condition comparison (dashed line in (b) represents minimum failure strain prediction for the constant lateral pressure system).

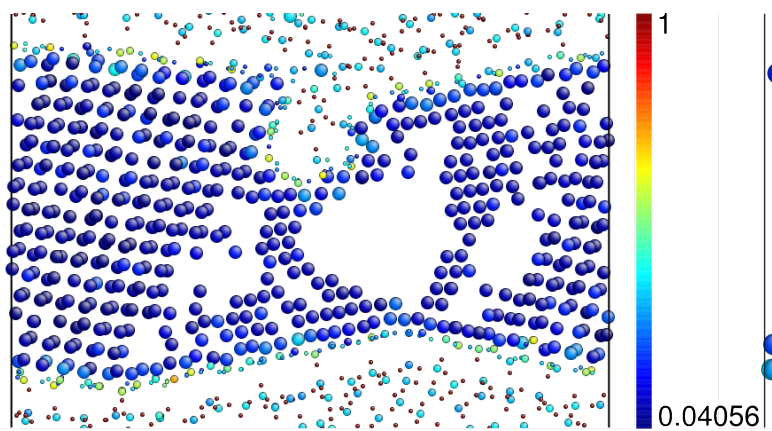

(a)

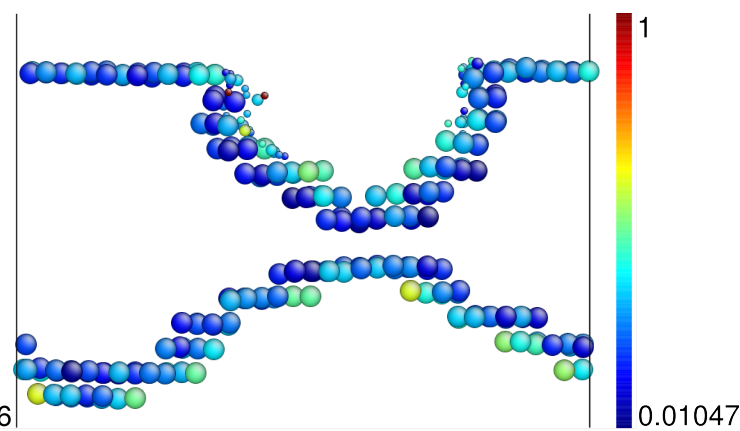

(b)

Figure 5. Normalized central symmetry parameter [46, 47] distribution for 110 strained fcc-Ni plates: (a) in water $\left(300 \mathrm{~K}, \mathrm{P}_{\text {lateral }}=\right.$ const, $\left.\varepsilon=0.76\right)$ and (b) pre-oxidized in vacuum $\left(300 \mathrm{~K}, \varepsilon_{\text {lateral }}=\right.$ const, $\left.\varepsilon=0.56\right)$.

The effects of $\mathrm{H}_{2} \mathrm{O}$ environment can be estimated by considering the potential energy responses (Figure 6a), which indicate that the structures in water nucleate dislocations with lower energy barriers than the structures in vacuum, in contrast to static QM-CADD calculations with a single $\mathrm{O}$ adatom [4]. This results in a lower failure strain than for the structures in vacuum. Yet it is also observed that the pre-oxidized structure yields significantly higher dislocation emission barriers for the second and third emissions than the structure in vacuum, in particular for the applied tensile stress (Figure 6b). We suggest that reduced triaxiality effect due to the water pressure could be attributed to the observed differences. Furthermore, since the pre-oxidized structures were equilibrated before applying the deformation, we suggest that the reduction of dislocation barriers for the structures in water can be also ascribed to 
insufficient time for the formation of a stable surface film due to the applied strain rate. This would be consistent with the rupture-slip dissolution mechanism [10,11], since rupture, as indicated by the increased initial dislocation emission barriers, is likely to occur with the pre-oxidized structures in vacuum, whereas dissolution and constant oxidation processes with low-barrier slip increments are applicable to the structures in water. The effects of elevated temperature at $600 \mathrm{~K}$ can be distinguished most clearly by reduction in dislocation nucleation barriers after transition to the necking failure mechanism (Figure 6a), which occurs earlier than for the analogous system at 300K. Likewise, the behavioral differences are manifested in the overall tensile stress responses (Figure 6b), which indicate the highest stiffness for the vacuum structure with closed notch, followed by the pre-oxidized notch structure in vacuum and the structures with $\mathrm{H}_{2} \mathrm{O}$ interface. The comparison between $300 \mathrm{~K}, 600 \mathrm{~K}$ and $900 \mathrm{~K}$ pre-oxidized plate structures in vacuum at 300K (Figure 7) indicates that the vacuum environment results in increased initial dislocation potential energy and tensile stress barriers in all cases, compared to a structure in water. Moreover, we find that increased reactivity at notch surface of the $900 \mathrm{~K}$ pre-oxidized structure (Table 2) may facilitate reduction in ductility due to an earlier transition to a necking failure mode.

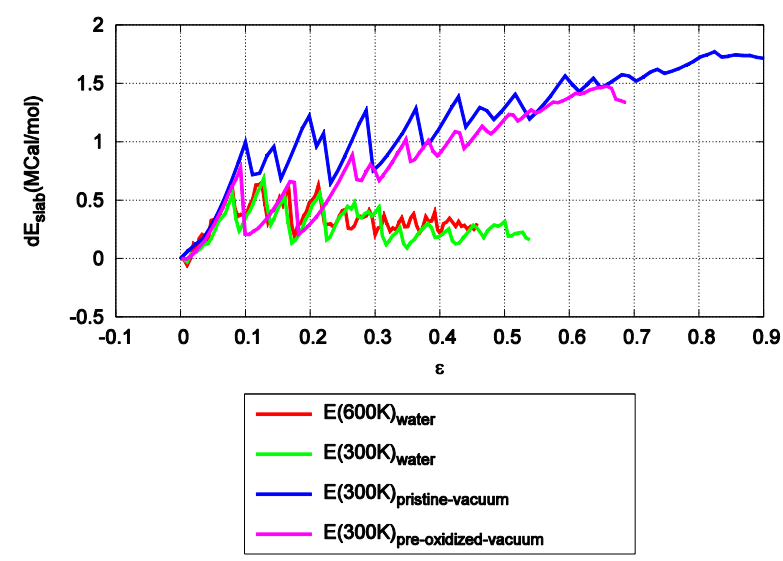

(a)

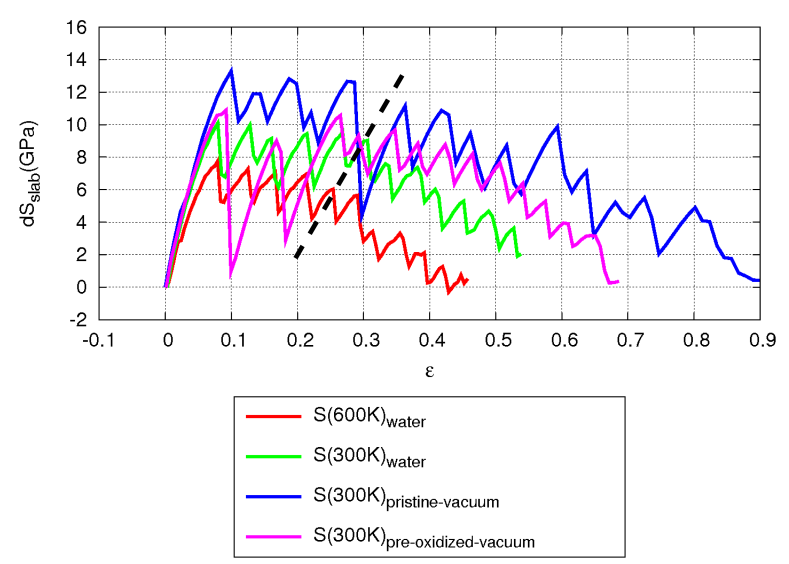

(b)

Figure 6. Potential energy (a) and tensile stress (b) vs. strain for 110 strained fcc-Ni plates: temperature and environment comparison (dashed line in (b) represents initiation of necking failure mode). 


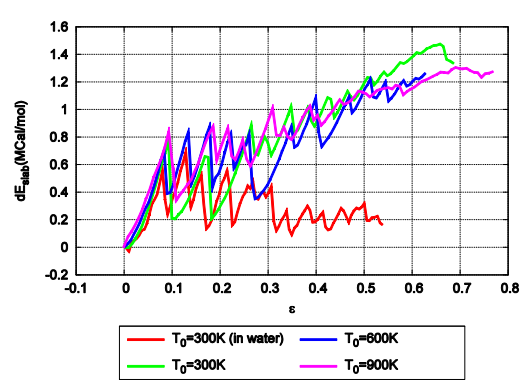

(a)

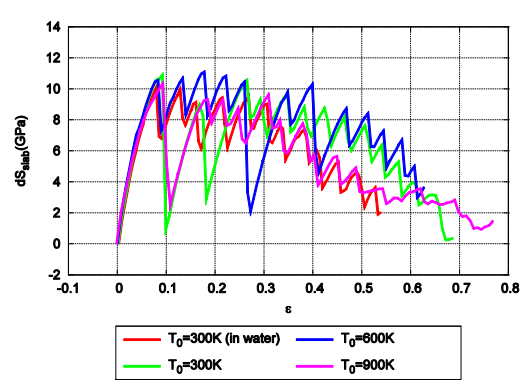

(b)

Figure 7. Potential energy (a) and tensile stress (b) vs. strain for 110 strained fcc-Ni plates in vacuum (300K): pre-oxidation state effect comparison.

Table 2. Oxidation species on notch surfaces of pre-oxidized equilibrated fcc-Ni plates.

\begin{tabular}{|l|r|r|r|}
\hline & $300 \mathrm{~K}$ & \multicolumn{1}{|l|}{$600 \mathrm{~K}$} & \multicolumn{2}{l|}{$900 \mathrm{~K}$} \\
\hline $\mathrm{OH}$ & 1 & 3 & 4 \\
\hline $\mathrm{H}_{2} \mathrm{O}$ (physisorbed) & 6 & 5 & 6 \\
\hline $\mathrm{H}_{3} \mathrm{O}$ & 2 & 1 & 6 \\
\hline $\mathrm{Ni}_{\mathrm{X}} \mathrm{O}$ & 0 & 0 & 4 \\
\hline
\end{tabular}

Due to the small system dimension of 2 unit cells, which corresponds to an aspect ratio of 3.5 with respect to the and dimensions of the system, for slip plane identification only the and direction 2-dimensional (2D) coordinates were used. Subsequently, the observed $\{113\}$ slip planes in the systems with fixed lateral dimension were identified, by comparison with the 3-dimensional orientation of the respective $\{111\}$ planes () , as $2 \mathrm{D}$ equivalents of the expected slip along $\{111\}$ planes for fcc metals. The latter deformation mode, due to the small system dimension and system periodicity, corresponds to a high density of $\{111\}$ dislocation jogs. The assumption was supported by the observation that no $\{113\}$ slip is reported for similar Ni structures with close to unity aspect ratios under analogous loading conditions [42]. The quasi 2D constraints were also attributed to the observed step formation mechanism, facilitated by an expanded dislocation core (Figure 9). Since the potential energy change for the transition did not indicate any metastable transition state, no transient grain formation was assumed to be present (Figure 10). The single dislocation barriers could be readily identified by consecutive peaks in the potential energy and stress plots (Figure 6). Likewise, it was observed that for all structures that contain a notch there occurs a transition between two approximately constant peak stress slopes after symmetry preserving $\{113\}$ dislocations start to nucleate, thus facilitating a necking type failure due to rising stress concentration (Figure 12a,c,d, Figure 11). Instead, for the structure with closed notch only single $\{113\}$ 
plane dislocations and no necking transition were observed (Figure 12b). Additionally we suggest that a flaw tolerance related size effect [51-53] due to the high value of surface-to-volume ratio [54] may manifest in the single type dislocation/grain formation mechanisms observed in this study.

(a)

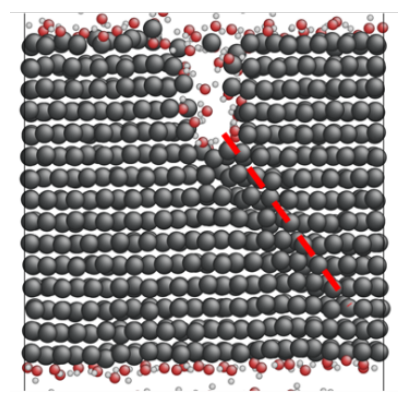

$\varepsilon=0.08$

\section{西}

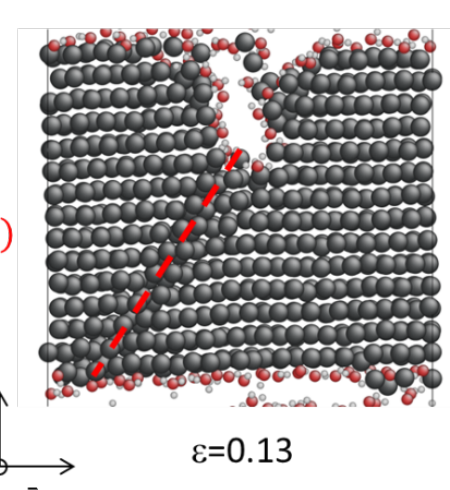

$[1 \overline{1}] \stackrel{\overrightarrow{[110]}}{\longrightarrow}$ (b)

$(\mathbf{1 3 1})$

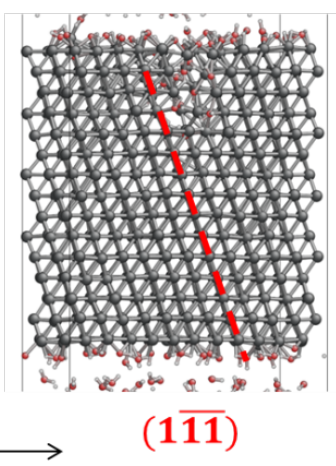

[21ㄹ] [011]

Figure 8. Dislocation planes for a 110 strained fcc-Ni plate in water $\left(600 \mathrm{~K}, \varepsilon_{\text {lateral }}=\right.$ const $)$.
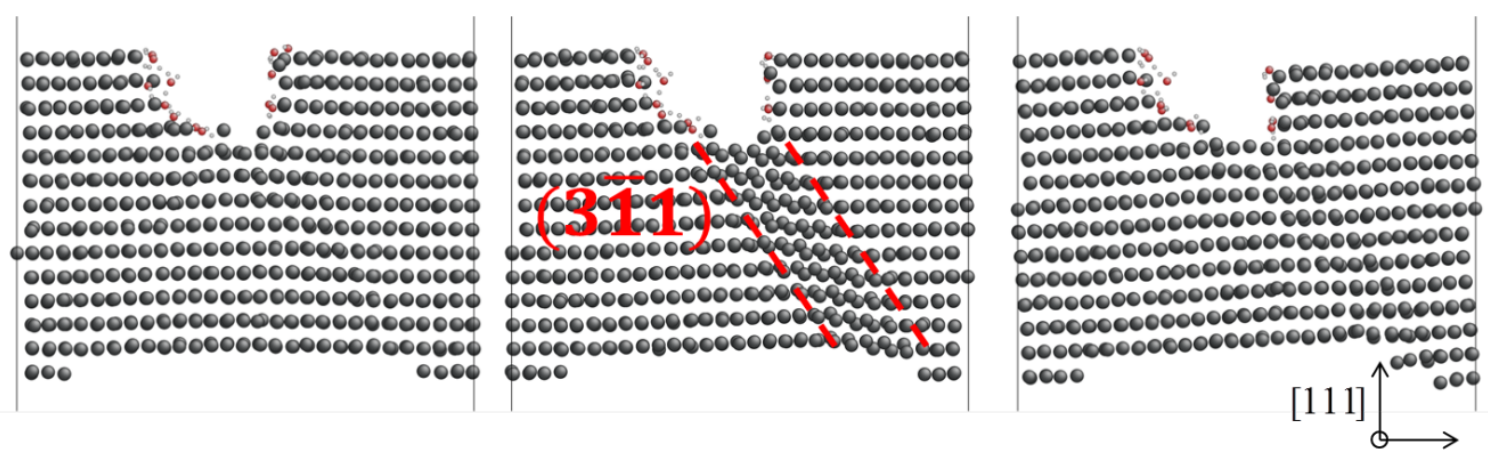

$[1 \overline{12}][1 \overline{1} 0]$

Figure 9. Step formation mechanism for a 110 strained pre-oxidized fcc-Ni plate in vacuum (300K, $\varepsilon_{\text {lateral }}=$ const, $\varepsilon=0.272$ ).

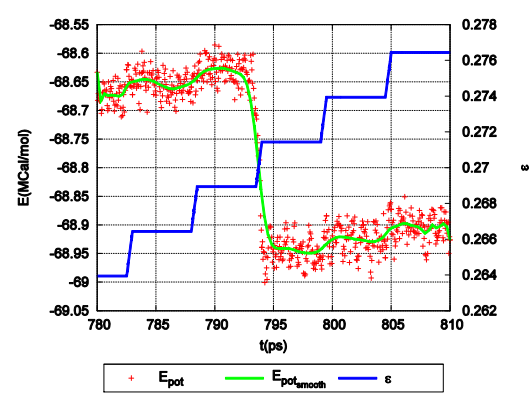


Figure 10. Potential energy and strain vs. time for a 110 strained pre-oxidized fcc-Ni plate (300K, $\varepsilon_{\text {lateral }}=$ const) during step formation transition.

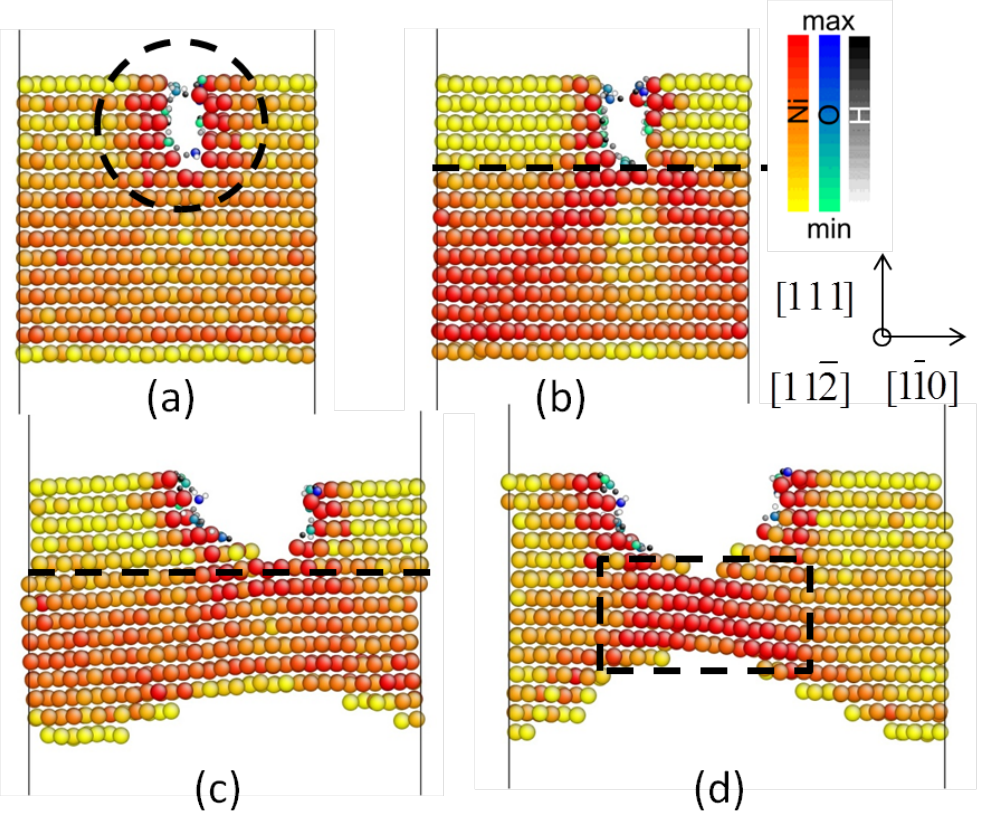

\begin{tabular}{|c|c|c|c|}
\hline configuration & $\varepsilon$ & $\mathrm{S}_{\min \mathrm{Ni}}(\mathrm{GPa})$ & $\mathrm{S}_{\max N i}(\mathrm{GPa})$ \\
\hline $\mathrm{a}$ & 0.03 & 10.8 & 14.9 \\
\hline$b$ & 0.09 & 13.5 & 19.1 \\
\hline C & 0.37 & 12.3 & 17.1 \\
\hline d & 0.52 & 11.2 & 16.0 \\
\hline
\end{tabular}

Figure 11. Octahedral stress distribution during neck formation for a 110 strained pre-oxidized fcc-Ni plate in vacuum $\left(300 \mathrm{~K}, \varepsilon_{\text {lateral }}=\right.$ const, $10 \mathrm{ps}$ time-averaged stress values with sampling frequency of 0.1 ps). Dashed lines indicate stress concentration regions. 


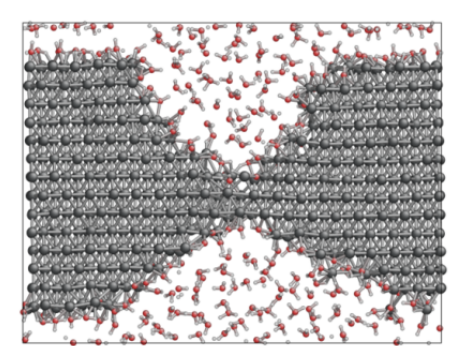

(a)

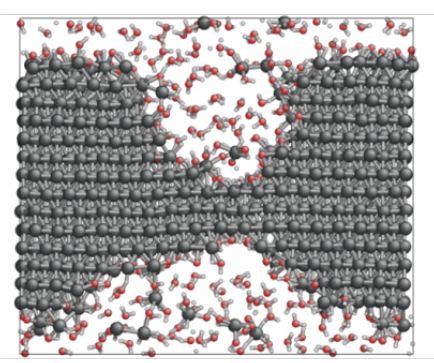

(c)

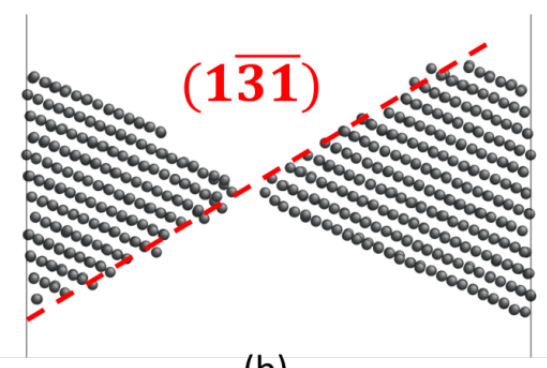

(b)

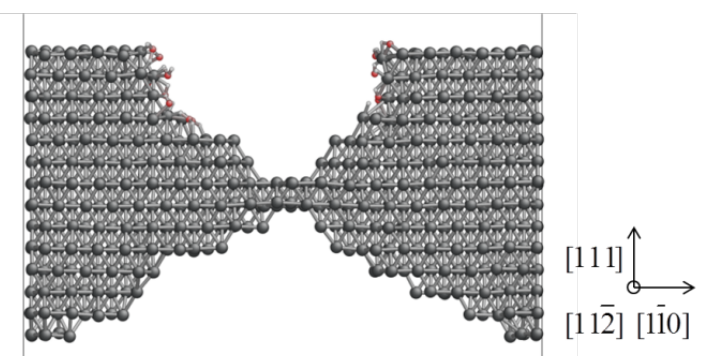

(d)

Figure 12. 110 strained fcc-Ni plate comparison $\left(\varepsilon_{\text {lateral }}=\right.$ const): structures in water at $300 \mathrm{~K}$ (a) and $600 \mathrm{~K}$ (c) and structures in vacuum without pre-oxidation (b) and with a pre-oxidized notch (d) (Ni - black, $\mathrm{O}-$ red, $\mathrm{H}$ - white).

The only reaction product in the $300 \mathrm{~K}$ simulations is $\mathrm{Ni}$ hydroxide, except for a few $\mathrm{Ni}\left(\mathrm{H}_{2} \mathrm{O}\right)_{\mathrm{X}}(\mathrm{X}=4$..6) clusters for the constant lateral pressure system. This is in marginal agreement with an ab initio phase diagram of [16], but not with experimental data [55], which predict the stability of $\mathrm{Ni}^{2+}$ species (Figure 15a,b). Since we consider $\mathrm{Ni}\left(\mathrm{H}_{2} \mathrm{O}\right)_{\mathrm{X}}$ species as equivalent to $\mathrm{Ni}^{\mathrm{Y}+}$, we suggest that larger time scale and the presence of surfaces other than $\{111\}$ could account for the differences from experiment. However, the oxide formation at $600 \mathrm{~K}$ is in agreement both with ab initio and experimental results $[16,55]$ (Figure 15c). Since no new oxide is formed during the deformation, we suggest again that lower loading rate, hence longer time scale, would be required for an $\mathrm{OH}$ dissociation reaction to occur, due to higher activation energy according to DFT calculations [17]. Interestingly, [16] also finds that the $\mathrm{Ni}\{111\} / \mathrm{H}_{2} \mathrm{O}$ interface always activates $\mathrm{H}_{2} \mathrm{O}$ dissociation regardless of the applied electrochemical potential. Based on the reaction species dynamics (Figure 15a,b) it could be also concluded that the boundary condition effect was manifested in the lower rate of increase of physisorbed $\mathrm{H}_{2} \mathrm{O}$ and $\mathrm{OH}$ groups for the constant lateral pressure system, presumably due to lower strain energy (Figure 4a) and smaller number of surface reaction sites (Figure 1, Figure 12a). Reaction products also include small numbers of $\left.\mathrm{Ni}_{(} \mathrm{H}_{2} \mathrm{O}\right)_{\mathrm{X}}(\mathrm{X}=2 . .5)$ type species for the system at $600 \mathrm{~K}$, originating primarily at surface steps and notch/crack surfaces (Figure 12c). These could be related to the reduction in Ni work function (ionization energy) upon $\mathrm{H}_{2} \mathrm{O}$ adsorption, as obtained by a many-electron embedding theory [18], and could also be indicative of weak $\mathrm{Ni}$ atom bonding at surfaces less stable than $\{111\}$. These are likewise in agreement with experimental 
results for $\mathrm{pH}<5$ [55]. The ionization energy argument was supported by a test simulation using a metadynamics approach $[30,56]$. According to it, $\mathrm{Ni}\left(\mathrm{H}_{2} \mathrm{O}\right)_{\mathrm{X}}$ a desorption barrier from a water-oxidized $\mathrm{Ni}$ (111) surface (Figure 13) is about $8 \mathrm{kcal} / \mathrm{mol}$ (Figure 14). The result is significantly less than the estimated $\mathrm{H}_{2} \mathrm{O}$ molecule physisorption energy of about $20.0 \mathrm{kcal} / \mathrm{mol}, \mathrm{H}_{2} \mathrm{O}$ dissociation activation energy of $22.1 \mathrm{kcal} / \mathrm{mol}$ [17] and the $\mathrm{Ni}\left(\mathrm{H}_{2} \mathrm{O}\right)_{4}$ binding energy of $50.5 \mathrm{kcal} / \mathrm{mol}$ in vacuum $(59.2 \mathrm{kcal} / \mathrm{mol}$ according to a DFT calculation).
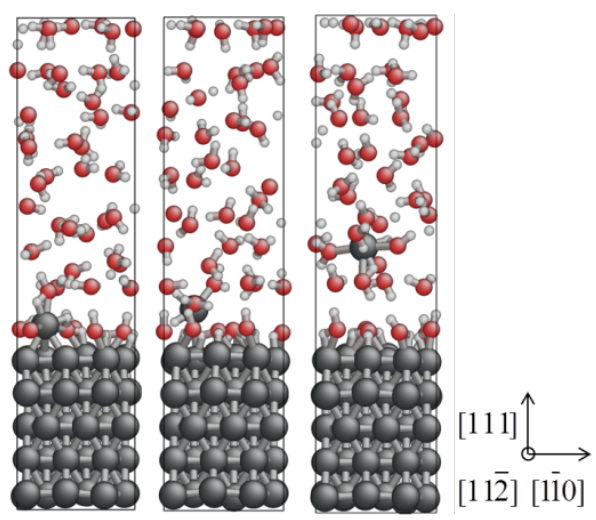

Figure 13. Configuration snapshots for $\mathrm{Ni}\left(\mathrm{H}_{2} \mathrm{O}\right)_{\mathrm{X}}$ desorption from $\mathrm{Ni}(111)$ surface as observed during the metadynamics simulations ( $\mathrm{Ni}$ - black, $\mathrm{O}$ - red, $\mathrm{H}$ - white).

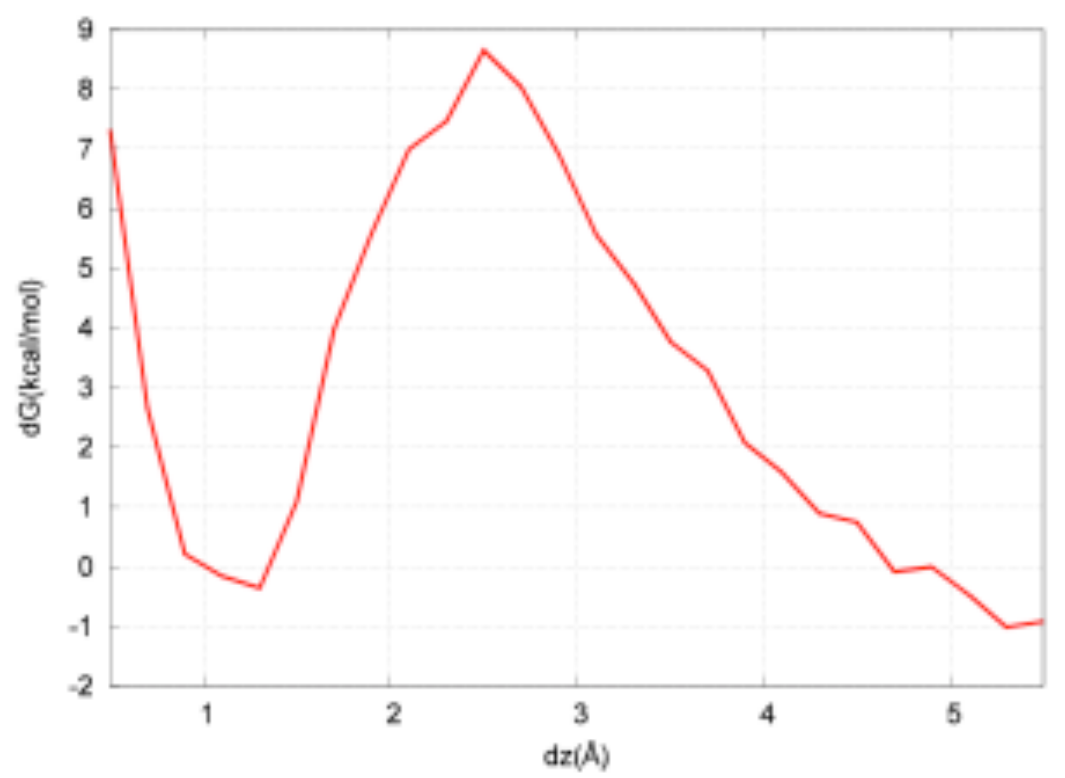

Figure 14. Free energy vs. distance from the top surface for $\mathrm{Ni}\left(\mathrm{H}_{2} \mathrm{O}\right)_{X}$ desorption from the $\mathrm{Ni}(111)$ surface.

Furthermore, it is observed that the hydrostatic pressure of water may correlate with the amount of $\mathrm{H}_{3} \mathrm{O}$ ions in the liquid (Figure 15b,c), since lower increase of $\mathrm{H}_{3} \mathrm{O}$ is observed at $600 \mathrm{~K}$ than at $300 \mathrm{~K}$. Likewise, the pressure rise is observed to be insignificant at $600 \mathrm{~K}$, as compared to $300 \mathrm{~K}$, presumably due to higher $\mathrm{H}_{2} \mathrm{O}$ diffusivity. We would like to mention again that the pressure effects could be slightly overestimated 
due to the comparatively high simulated overall pressure level (section 1). It should be added that the absence of oxide layers formation, which may occur upon application of external electric field [15], precludes stress corrosion cracking effects as observed in [8].

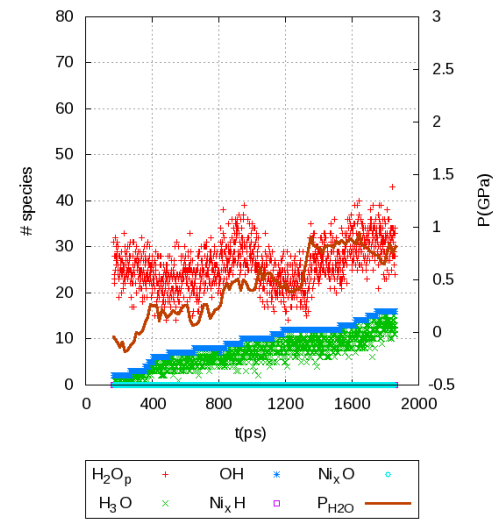

(a)

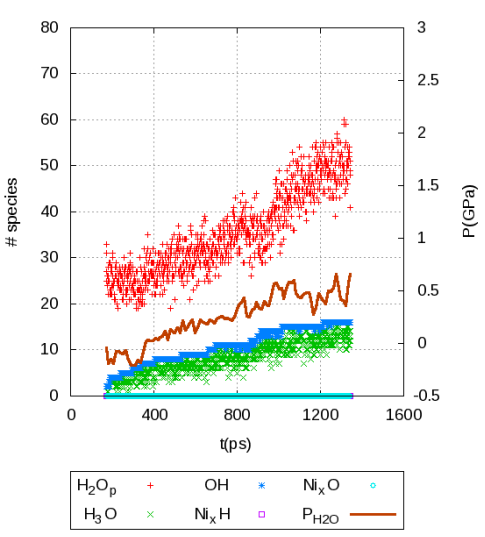

(b)

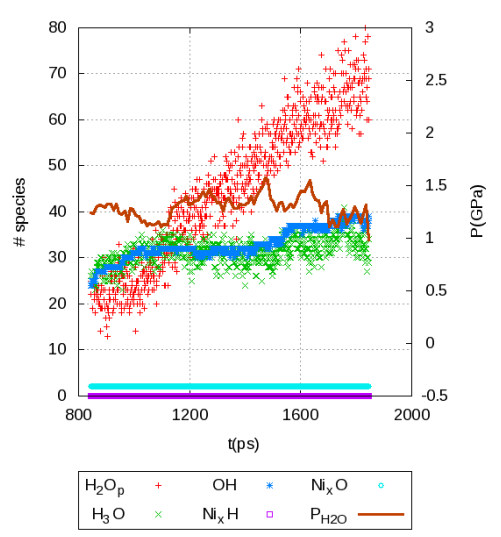

(c)

Figure 15. Reaction species $\left(\mathrm{H}_{2} \mathrm{O}_{\mathrm{p}}-\right.$ physisorbed $\left.\mathrm{H}_{2} \mathrm{O}\right)$ and water pressure vs. time for 110 strained fcc-Ni plate in water: $300 \mathrm{~K}$ systems with $\mathrm{P}_{\text {lateral }}=$ const (a) and $\varepsilon_{\text {lateral }}=$ const (b), and a $\varepsilon_{\text {lateral }}=$ const system at $600 \mathrm{~K}$ (c).

\section{Conclusions}

Ni metal nanoplate stress corrosion cracking behavior at different temperatures and system conditions has been studied by reactive molecular dynamics simulations. Our study indicates that increased stress triaxiality reduces $\mathrm{Ni}$ strength through obstruction of twinning dislocation failure mechanisms and activation of new, system periodicity affected, slip mechanisms and increases reactivitydue to higher strain energy. Likewise, it is found that pre-oxidation of defect surfaces may significantly increase dislocation emission barriers, corresponding to thin film rupture, whereas constant pressure corrosive environment may reduce the barriers, depending on the applied strain rate.

The overall effect of corrosive environment results in lower material failure strain and lower strain energy capacity, as compared to pristine structures in vacuum, due to enabled necking type transformations and reduced dislocation barriers. Elevated temperature below an active oxide formation temperature range, at a strain rate above that of stable surface layer formation, reduces material's ductility and strength due to reduced dislocation emission barriers, increased reactivity and dissolution at the surfaces. Additionally, a possible Ni corrosive dissolution mechanism, based on water adsorption, is identified by comparison of Ni dissolution, water molecule adsorption and dissociation energies. This mechanism was confirmed by DFT-calculations and metadynamics simulations, showing good agreement between ReaxFF and DFT for 
$\mathrm{Ni}$-ion complex dissolution in vacuum and low barriers for ion release from the metal surface from metadynamics simulations.

\section{Acknowledgements}

We acknowledge funding from the National Energy Technology Laboratory, US Department of Energy, under Award No. DE-FE0005867.

\section{References}

[1] N.E. Dowling, Mechanical Behavior of Materials: Engineering Methods for Deformation, Fracture, and Fatigue, 3rd ed., Prentice Hall, 2006.

[2] S.P. Lynch, Mechanisms and kinetics of environmentally assisted cracking: current status, issues, and suggestions for further work, Metallurgical and Materials Transactions A, 44 (2013) 1209-1229.

[3] G.S. Was, D. Farkas, I.M. Robertson, Micromechanics of dislocation channeling in intergranular stress corrosion crack nucleation, Current Opinion in Solid State and Materials Science, 16 (2012) 134142.

[4] R.J. Zamora, A.K. Nair, R.G. Hennig, D.H. Warner, Ab initio prediction of environmental embrittlement at a crack tip in aluminum, Physical Review B (Condensed Matter and Materials Physics), 86 (2012) 060101 (060105 pp.).

[5] S. Yi, P. Qing, L. Gang, Quantum mechanical modeling of hydrogen assisted cracking in aluminum, Physical Review B (Condensed Matter and Materials Physics), 88 (2013) 104109 (104106 pp.).

[6] J. Song, W.A. Curtin, A nanoscale mechanism of hydrogen embrittlement in metals, Acta Materialia, 59 (2011) 1557-1569.

[7] J. Song, W.A. Curtin, Atomic mechanism and prediction of hydrogen embrittlement in iron, Nat Mater, 12 (2013) 145-151.

[8] N.K. Das, K. Suzuki, K. Ogawa, T. Shoji, Early stage SCC initiation analysis of fcc Fe-Cr-Ni ternary alloy at $288^{\circ} \mathrm{C}$ : A quantum chemical molecular dynamics approach, Corrosion Science, 51 (2009) 908-

913.

[9] E.A.A. Jarvis, R.L. Hayes, E.A. Carter, Effects of Oxidation on the Nanoscale Mechanisms of Crack Formation in Aluminum, ChemPhysChem, 2 (2001) 55-59.

[10] P.L. Andresen, F.P. Ford, Life prediction by mechanistic modeling and system monitoring of environmental cracking of iron and nickel alloys in aqueous systems, Materials Science \& Engineering A: Structural Materials: Properties, Microstructure and Processing, A103 (1988) 167-184.

[11] T. Shoji, L. Zhanpeng, N.K. Das, H. Murakami, Y. Takeda, T. Ismail, Modeling stress corrosion cracking growth rates based upon the effect of stress/strain on crack tip interface degradation and oxidation reaction kinetics, in, ASME, New York, NY, USA, 2009, pp. 1081-1100.

[12] M.M. Hall, Jr., An alternative to the Shoji crack tip strain rate equation, Corrosion Science, 50 (2008) 2902-2905.

[13] Y.S. Lim, H.P. Kim, S.S. Hwang, Microstructural characterization on intergranular stress corrosion cracking of Alloy 600 in PWR primary water environment, Journal of Nuclear Materials, 440 (2013) 4654. 
[14] K. Stiller, Investigations of grain boundary microchemistry in nickel base superalloys, Surface Science, 246 (1991) 225-230.

[15] O. Assowe, O. Politano, V. Vignal, P. Arnoux, B. Diawara, O. Verners, A.C.T. Van Duin, Reactive molecular dynamics of the initial oxidation stages of $\mathrm{Ni}(111)$ in pure water: Effect of an applied electric field, Journal of Physical Chemistry A, 116 (2012) 11796-11805.

[16] C. Taylor, R.G. Kelly, M. Neurock, First-Principles Calculations of the Electrochemical Reactions of Water at an Immersed Ni ( 111 ) /H2O Interface, Journal of the Electrochemical Society, 153 (2006) E207-E214.

[17] A.A. Phatak, W.N. Delgass, F.H. Ribeiro, W.F. Schneider, Density functional theory comparison of water dissociation steps on $\mathrm{Cu}, \mathrm{Au}, \mathrm{Ni}, \mathrm{Pd}$, and Pt, Journal of Physical Chemistry C, 113 (2009) 72697276.

[18] Y. Hong, J.L. Whitten, The adsorption of water and hydroxyl on Ni(111), Surface Science, 223 (1989) 131-150.

[19] LAMMPS Users Manual, in: n/a.

[20] S. Plimpton, Fast Parallel Algorithms for Short-Range Molecular Dynamics, Journal of Computational Physics, 117 (1995) 1-19.

[21] A.C.T. Van Duin, S. Dasgupta, F. Lorant, W.A. Goddard Iii, ReaxFF: A reactive force field for hydrocarbons, Journal of Physical Chemistry A, 105 (2001) 9396-9409.

[22] G. Simmons, H. Wang, Single crystal elastic constants and calculated aggregate properties. A handbook, MIT Press, London, UK, 1971.

[23] J.E. Mueller, A.C.T. van Duin, W.A. Goddard, Development and Validation of ReaxFF Reactive Force Field for Hydrocarbon Chemistry Catalyzed by Nickel, The Journal of Physical Chemistry C, 114 (2010) 4939-4949.

[24] J.A. Zimmerman, H. Gao, F.F. Abraham, Generalized stacking fault energies for embedded atom FCC metals, Modelling and Simulation in Materials Science and Engineering, 8 (2000) 103-115.

[25] P.M. Gullett, M.F. Horstemeyer, M.I. Baskes, H. Fang, A deformation gradient tensor and strain tensors for atomistic simulations, Modelling and Simulation in Materials Science and Engineering, 16 (2008) 015001.

[26] M. Sennour, L. Marchetti, F. Martin, S. Perrin, R. Molins, M. Pijolat, A detailed TEM and SEM study of Ni-base alloys oxide scales formed in primary conditions of pressurized water reactor, Journal of Nuclear Materials, 402 (2010) 147-156.

[27] A. Taylor, Lattice Parameters of Binary Nickel Cobalt Alloys, Journal of the Institute of Metals, 77 (1950) 585-594.

[28] Collective variables module reference manual for LAMMPS, in, 2014.

[29] M. Bonomi, D. Branduardi, G. Bussi, C. Camilloni, D. Provasi, P. Raiteri, D. Donadio, F. Marinelli, F. Pietrucci, R.A. Broglia, M. Parrinello, PLUMED: A portable plugin for free-energy calculations with molecular dynamics, Computer Physics Communications, 180 (2009) 1961-1972.

[30] A. Barducci, G. Bussi, M. Parrinello, Well-Tempered Metadynamics: A Smoothly Converging and Tunable Free-Energy Method, Physical Review Letters, 100 (2008) 020603.

[31] G. Kresse, J. Hafner, Ab initio molecular dynamics for liquid metals, Physical Review B, 47 (1993) 558-561.

[32] G. Kresse, J. Furthmüller, Efficient iterative schemes for ab initio total-energy calculations using a plane-wave basis set, Physical Review B, 54 (1996) 11169-11186.

[33] P.E. Blöchl, Projector augmented-wave method, Physical Review B, 50 (1994) 17953-17979.

[34] G. Kresse, D. Joubert, From ultrasoft pseudopotentials to the projector augmented-wave method, Physical Review B, 59 (1999) 1758-1775.

[35] J.P. Perdew, K. Burke, M. Ernzerhof, Generalized Gradient Approximation Made Simple, Physical Review Letters, 77 (1996) 3865-3868.

[36] M. Methfessel, A.T. Paxton, High-precision sampling for Brillouin-zone integration in metals, Physical Review B, 40 (1989) 3616-3621. 
[37] S. Grimme, S. Ehrlich, L. Goerigk, Effect of the damping function in dispersion corrected density functional theory, Journal of Computational Chemistry, 32 (2011) 1456-1465.

[38] E. Engel, R.M. Dreizler, Density Functional Theory: An Advanced Course, Springer, 2011.

[39] G.H.F. Diercksen, S. Wilson, Methods in Computational Molecular Physics, in: Nato Science Series C, Springer, 1982.

[40] P. Pulay, Convergence acceleration of iterative sequences. The case of SCF iteration, Chemical Physics Letters, 73 (1980) 393-398.

[41] H.J. Monkhorst, J.D. Pack, Special points for Brillouin-zone integrations, Physical Review B, 13 (1976) 5188-5192.

[42] T. Kitamura, K. Yashiro, R. Ohtani, Atomic simulation on deformation and fracture of nano-single crystal of nickel in tension, JSME International Journal, Series A (Solid Mechanics and Material Engineering), 40 (1997) 430-435.

[43] Y. Bao, T. Wierzbicki, On fracture locus in the equivalent strain and stress triaxiality space, International Journal of Mechanical Sciences, 46 (2004) 81-98.

[44] M.S. Mirza, D.C. Barton, P. Church, The effect of stress triaxiality and strain-rate on the fracture characteristics of ductile metals, Journal of Materials Science, 31 (1996) 453-461.

[45] G.P. Potirniche, M.F. Horstemeyer, G.J. Wagner, P.M. Gullett, A molecular dynamics study of void growth and coalescence in single crystal nickel, International Journal of Plasticity, 22 (2006) 257-278.

[46] J. Li, AtomEye: An efficient atomistic configuration viewer, Modelling and Simulation in Materials Science and Engineering, 11 (2003) 173-177.

[47] C.L. Kelchner, S.J. Plimpton, J.C. Hamilton, Dislocation nucleation and defect structure during surface indentation, Physical Review B (Condensed Matter), 58 (1998) 11085-11088.

[48] D. Hull, D.J. Bacon, Introduction to Dislocations, 5 ed., Butterworth-Heinemann, 2011.

[49] J. Schiotz, A.E. Carlsson, The influence of surface stress on dislocation emission from sharp and blunt cracks in fcc metals, Philosophical Magazine A (Physics of Condensed Matter: Structure, Defects and Mechanical Properties), 80 (2000) 69-82.

[50] L. Hung, E.A. Carter, Ductile processes at aluminium crack tips: Comparison of orbital-free density functional theory with classical potential predictions, Modelling and Simulation in Materials Science and Engineering, 19 (2011).

[51] D. Sen, A.P. Garcia, M.J. Buehler, Mechanics of Nano-Honeycomb Silica Structures: SizeDependent Brittle-to-Ductile Transition, Journal of Nanomechanics and Micromechanics, 1 (2011) 112118 .

[52] M.J. Buehler, Y. Haimin, G. Huajian, J. Baohua, Cracking and adhesion at small scales: atomistic and continuum studies of flaw tolerant nanostructures, Modelling and Simulation in Materials Science and Engineering, 14 (2006) 799-816.

[53] L. Qiang, M. Nigel, G.C. Schatz, T. Belytschko, Nanoscale fracture of tetrahedral amorphous carbon by molecular dynamics: flaw size insensitivity, Physical Review B (Condensed Matter and Materials Physics), 77 (2008) 014109-014101.

[54] J.N. Ding, Y.G. Meng, S.Z. Wen, Specimen size effect on mechanical properties of polysilicon microcantilever beams measured by deflection using a nanoindenter, Materials Science \& Engineering B (Solid-State Materials for Advanced Technology), B83 (2001) 42-47.

[55] B. Beverskog, I. Puigdomenech, Revised Pourbaix diagrams for nickel at 25-300C, Corrosion Science, 39 (1997) 969-980.

[56] B. Ensing, M. De Vivo, Z. Liu, P. Moore, M.L. Klein, Metadynamics as a Tool for Exploring Free Energy Landscapes of Chemical Reactions, Accounts of Chemical Research, 39 (2005) 73-81. 
Supplementary Material for Online Publication only
Click here to download Supplementary Material for Online Publication only: Ni_slab_H2O.cfg Supplementary Material for Online Publication only
Click here to download Supplementary Material for Online Publication only: Ni_slab_H2O.C

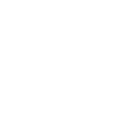
$\sqrt{3}$

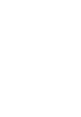

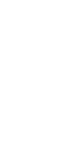

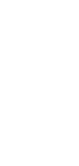

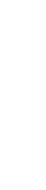
列 . . . . .

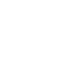
.

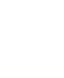

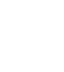

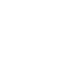

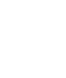

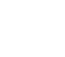

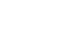

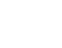

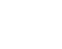

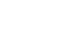

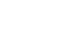

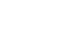

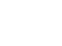

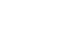

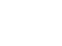

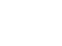

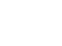

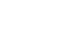


Supplementary Material for Online Publication only
Click here to download Supplementary Material for Online Publication only: Ni_slab_oxidized.cfg

Supplementary Material for Online Publication only
Click here to download Supplementary Material for Online Publication only: Ni_slab_oxidized.cfg 

Supplementary Material for Online Publication only
Click here to download Supplementary Material for Online Publication only: Ni_slab.cfg Click here to download Supplementary Material for Online Publication only: Ni_slab.cfg

(1)

(1)

$\sqrt{10}$

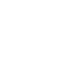
$\sqrt{10}$ $\sqrt{10}$ 

Supplementary Material for Online Publication only
Click here to download Supplementary Material for

Click here to download Supplementary Material for Online Publication only: POSCAR_Ni_111_cluster_off_surface -

ation only: POSCAR_Ni_111_cluster_off_surface 11_cluster_off_surface (n) (1)

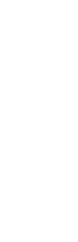
西 西 . . . . . . . . . . . . 
